\title{
EFFECT OF TEMPERATURE DISTRIBUTION ON PREDICTING QUALITY OF MICROWAVE DEHYDRATED FOOD
}

\author{
Mohammad U. H. Joardder ${ }^{1,2 *}$, Azharul Karim ${ }^{1}$ and Chandan Kumar ${ }^{1}$ \\ ${ }^{1}$ Faculty of Engineering and Science, Queensland University of Technology, \\ Brisbane, Queensland 4001,Australia \\ Email: muhjoardder@gmail.com Phone : +61415678420 \\ ${ }^{2}$ Department of Mechanical Engineering, Rajshahi University of Engineering and \\ Technology, Bangladesh.
}

\begin{abstract}
During food drying, many other changes occur simultaneously, resulting in an improved overall quality. Among the quality attributes, the structure and its corresponding color influence directly or indirectly other properties of food. In addition, these quality attributes are affected by process conditions, material components and the raw structure of the foodstuff. In this work, the temperature distribution within food materials during microwave drying has been taken into consideration to observe its role in color modification. In order to determine the temperature distribution of microwave-dried food (apple), a thermal imaging camera has been used. The image acquired from the digital camera has been analysed using image $\mathbf{J}$ software in order to get the color change of fresh and dried apple. The results show that temperature distribution plays an important role in determining the quality of the food. The thermal imaging camera was deployed to observe the temperature distribution within food materials during drying. It is clearly observed from the higher value of $\left(\Delta E_{R G B}=102\right)$ and the uneven color change that uneven temperature distribution can influence customer perceptions of the quality of dried food. Simulation of a mathematical model of temperature distribution during microwave drying can make it possible to predict the colour and texture of the microwaved food.
\end{abstract}

Keywords: Food drying; temperature distribution; texture; colour; quality prediction.

\section{INTRODUCTION}

Fruits and vegetables are important sources of essential dietary nutrients such as vitamins, minerals and fiber. Since the moisture content of fresh fruits and vegetables is more than $80 \%$, they are classified as highly perishable commodities (Orsat, Yang, Changrue, \& Raghavan, 2007). Food is one of the most complex materials in its natural form and the fundamental understanding of food drying has not been fully established (Barati \& Esfahani, 2012). The lack of proper processing causes considerable damage and wastage of seasonal fruits in many countries, which is estimated to be $30-40 \%$ in developing countries (Karim \& Hawlader, 2005). Drying of foodstuffs is an important and the oldest method of food processing. Many physical and chemical changes occur in foods during the drying process. The quality of dehydrated products is affected by a number of factors and is dependent on the quality of the raw material, method of preparation, processing treatments and drying conditions (Rahman, 2009). Better stability and quality can be obtained by controlling the fresh or optimum conditions of the raw materials (Perera, 2005). Consumers select their foods in the supermarket 
primarily based on visual perception and often this is the only direct information received from the product. The visual sensation is a mix of the color, shape and size of the product (Paulus \& Schrevens, 1999). The color of processed food materials is a great influential factor in the acceptance by the consumer. Therefore, an appealing color makes food more acceptable. However, food color changes due to heat and mass transfer during drying. One of the causes of color changes is the browning reaction that takes place during drying. This reaction is affected not only by the temperature but also by its distribution. Furthermore, the temperature distribution influences the moisture transfer from the food materials during drying. The cell membrane is destroyed when it is processed at a high temperature. When the drying temperature is high, cell membranes rupture and release water into the extracellular space and therefore the transport of water to the outside occurs predominantly through the extracellular space (Halder, Dhall, \& Datta, 2011). Therefore, temperature distribution is revealed to be influential for both the appearance and the structure of dried food materials. Thus, prediction of the temperature distribution during drying can provide a controlled optical appearance. In this study, the uneven nature of the temperature distribution during microwave drying has been examined. Moreover, the role of the temperature distribution in food quality has also been investigated by observing its color and appearance.

\section{Raw Material}

\section{MATERIAL AND METHOD}

Gala apples were purchased from a local supermarket and stored at ambient temperature $\left(20^{\circ} \mathrm{C}\right)$ until the moment of the experiment. Samples for the drying experiments were discs of apple tissue (40 $\mathrm{mm}$ in diameter and $5 \mathrm{~mm}$ thickness) cut parallel to the main axis of the fruit. Drying was performed in order to develop non-uniform temperature distribution as this is one of the features of microwave heating (Chou \& Chua, 2001). For microwave heating we used a Panasonic 32L mid-sized stainless steel inverter sensor microwave oven NN-SD691S. With ten variable power levels, this $1100 \mathrm{~W}$ microwave allows different types of foods to be defrosted, reheated and cooked quickly. An apple slice was placed in the microwave oven for 10 minutes at $200 \mathrm{~W}$ power. Further heating was then conducted to investigate the effect of temperature on appearance.

\section{Digital and Thermal Image Acquisition}

A thermal image camera allows monitoring of the temperature distribution in heated material. We used a FLIR i5 thermal camera, which provides 10000 pixel images, and allows a temperature accuracy calibrated within $\pm 2{ }^{\circ} \mathrm{C}$ or $2 \%$ of the reading to meet the standard. It is capable of tracing the optimized temperature range from -20 to $250^{\circ} \mathrm{C}$. Digital images were obtained using an 8.0 megapixel camera. These images were stored in bitmap graphic format.

\section{Image analysis}

Digital image analysis in the RGB color model was done using color picker software, yielding RGB-triplets for every pixel on the image, with red $(R)$, green $(G)$ and blue (B). 
The intensities of the mentioned colors range from 0 to 255. Color analysis was done in terms of hue angle and color change. The hue angle value corresponds to whether the object is red, orange, yellow green, blue, or violet (Mohammadi, Rafiee, EmamDjomeh, \& Keyhani, 2008). Hue angle is defined as (.1):

$$
\begin{gathered}
h_{0}=\tan ^{-1}\left(\frac{\sqrt{3}(G-B)}{2 R-G-B}\right) \\
\tanh ^{0}=\left(\frac{\sqrt{3}(G-B)}{2 R-G-B}\right)
\end{gathered}
$$

Color changes in the RGB color model were defined as:

$$
\Delta E_{R G B}=\sqrt{\left[(\Delta R)^{2}+(\Delta G)^{2}+(\Delta B)^{2}\right]}
$$

where $\Delta E$ is the value of the color change in the raw apple slice and dehydrated apple.

\section{RESULTS AND DISCUSSION}

\section{Temperature Distribution of Food Materials}

Due to the non-uniform electromagnetic field, the microwave oven affords non-uniform heating (Wang \& Chen, 2003). The thermal images shown in Figure 1 provide a clear indication of the non-uniform heat transfer.

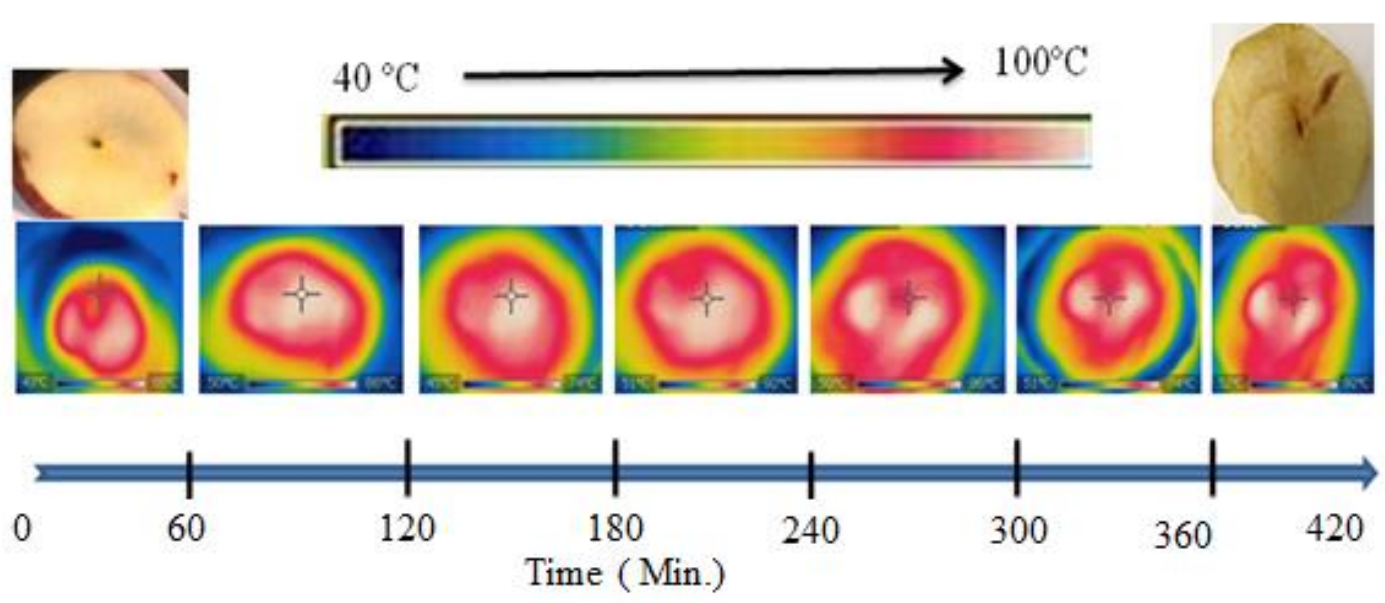

Figure 1. Temperature distribution in apple slice during drying.

The temperature distribution can be presented as the maximum, minimum, average temperature of the sample, as well as the central temperature of the apple slice. Figure 1 compares thetemperatures obtained from thermal images, where the uneven distribution of temperature is shown in different colors. Further analysis of the temperature distribution, as shown in Figure 2, demonstrates the minimum, maximum, center and average temperatures within the sample. 


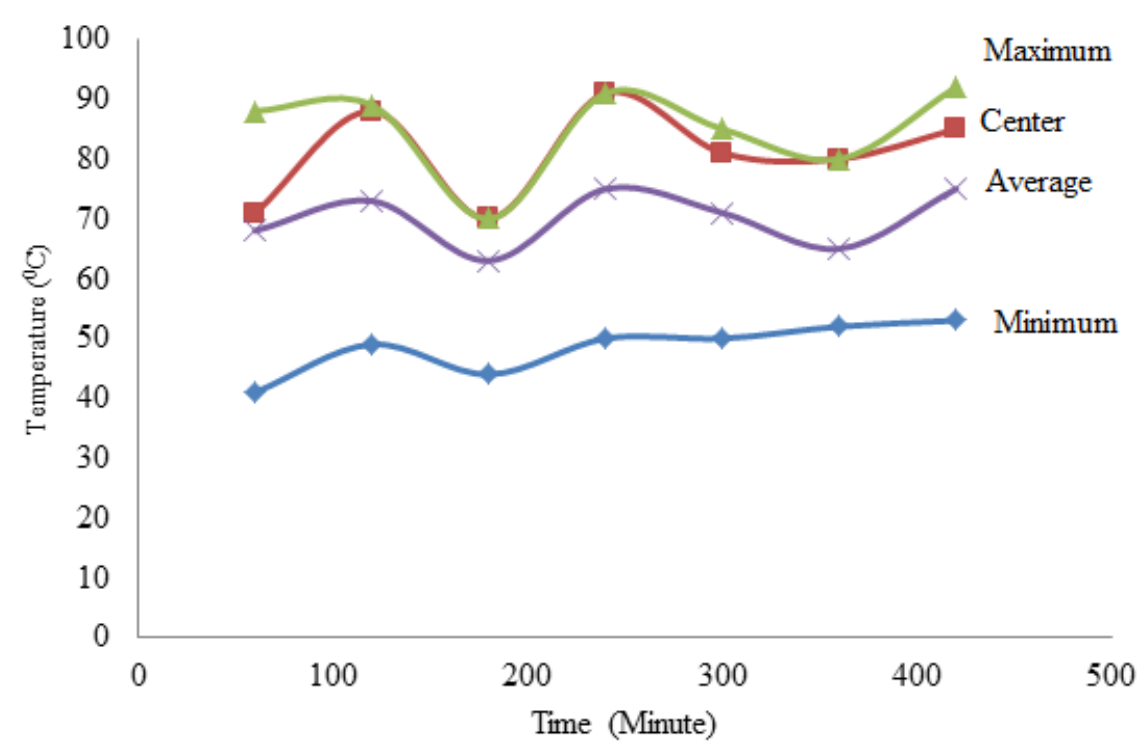

Figure 2. Temperature distribution at different times of drying.

The minimum temperature increases almost constantly throughout the process, with the exception of the fluctuation at $200 \mathrm{~min}$. On the other hand, the maximum, center and average temperatures show very similar fluctuation. This fluctuation may be caused by changesin the water content and temperature redistribution within the sample (Joardder, Kumar, \& Karim, 2013). In other words, the temperature fluctuation that is caused at different points at different times within the sample is either due to moisture content or to the convective heat transfer from water to solid networks of food tissue.

\section{Color Changes}

Usually during drying, the color may change due to a number of chemical and biochemical reactions (Maskan, Kaya, \& Maskan, 2002). From Table 1 it can be clearly seen that the color of the raw materials in the entire sample is consistent. On the other hand, the dried food color shows a random nature. The RGB color calculator was deployed in order to identify representative colors. The total color change $\Delta E_{R G B}$ was found to be 102.4. This implies that the degradation rate of color becomes faster with increasing temperature. This indicates that high energy transferred to the inside of the food material causes the color changes. In addition, the hue angle was found to be within the range of 84-94.

\section{Texture of the Dried Foods}

Texture is a difficult property to define. It can be considered an external reflection of the micro and macro structural characteristics of a food product (Aguilera \& Stanley, 1999). The insight of texture is a combination of information from several senses (Wilkinson, Dijksterhuis, \& Minekus, 2000). The texture of fruits and vegetables is affected by drying processes and it is strongly associated with the composition and structure of cell walls (Reeve, 1970). 
Table 1. Color parameters of raw and dehydrated apple samples and respective color (RGB color model)

\begin{tabular}{clllll}
\hline Apple Slice & Points & R & G & B & Color \\
\hline \multirow{5}{*}{ Raw } & 1 & 247 & 199 & 100 & \\
& 2 & 251 & 214 & 139 & \\
& 3 & 251 & 198 & 129 & \\
& 4 & 254 & 209 & 107 & \\
& 5 & 224 & 184 & 122 & \\
& Average & 245.5 & 200.8 & 119.4 & \\
& 1 & 189 & 156 & 82 & \\
& 2 & 212 & 177 & 107 & \\
\hline \multirow{5}{*}{ Dehydrated } & 3 & 214 & 196 & 133 & \\
& 4 & 134 & 109 & 41 & \\
& 5 & 119 & 64 & 28 & \\
& Average & 173.6 & 140.4 & 78.2 & \\
\hline
\end{tabular}

Due to uneven heating, microwave drying provides a significantly heterogeneous structure and texture of the sample. To demonstrate this, the apple slice was heated further and the structure shown in Figure 3 was found.
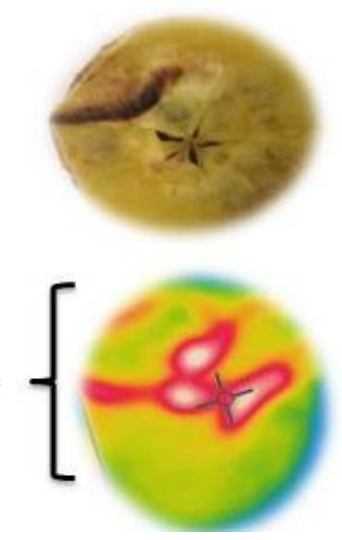
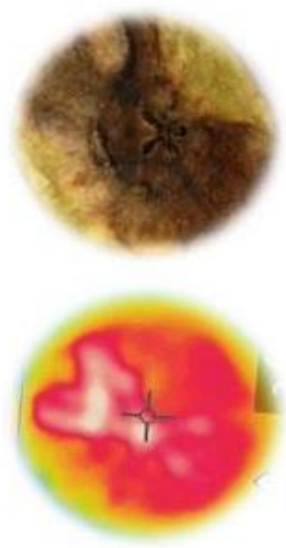
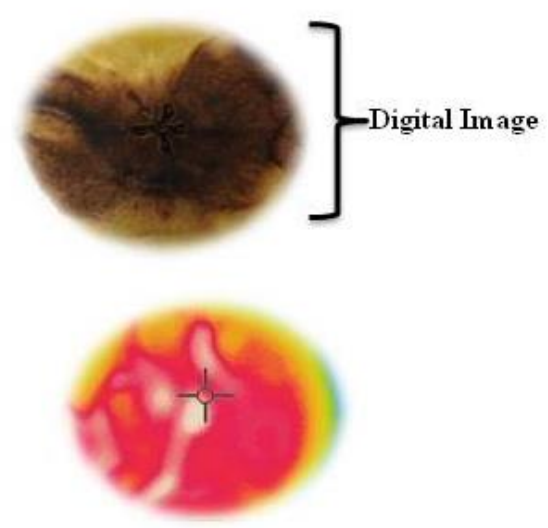

Figure 3. Heterogeneous structure of apple slice due to non-uniform heating.

A positive correlation was found between thermal images and digital images. This indicates that prior modeling of the temperature distribution of microwave heating of the food materials can allow the prediction of dried food quality (Kumar, Karim, Joardder, \& Miller, 2012), and especially the color, texture and structure of the dehydrated foods. Since temperature distribution causes moisture distribution and structural modification, the image of the food product can manifest its moisture content and structural conditions. The projection of light (photons) at diverse angles due to the material's physiological criteria and interaction with molecules causes the scattering of light on the surface of the materials. Interestingly, this scattering of photons is influenced by the moisture content of the materials. Romano, Argyropoulos, Nagle, Khan, and Müller (2012) found that higher moisture content causes more intense light than reduced moisture content in a sample. Structural properties also influence the photon migration, with a greater backward direction in the sample, which is more 
intense for softer tissue than for firmer tissues having less intercellular space and more robust cell walls (Peng \& Lu, 2006). Recently, researchers have been working on moisture and temperature distribution modeling for predicting the temperature distribution during drying (Rakesh, Seo, Datta, McCarthy, \& McCarthy, 2010).

\section{CONCLUSION}

Thermal images of apple slices demonstrated non-uniform temperature distribution during drying, which was due to the uneven nature of microwave heating, the food microstructure and the moisture content of the food material. On the other hand, digital image colors can manifest the moisture distribution and structural criteria. The total color change is 102.4 and the hue angle of 84-94 implies faster color changes in microwave heating. Better quality dried food can be achieved by controlling these huge color change values. The present study confirms previous findings and contributes additional evidence that suggests that the modeling and simulation of temperature distribution can provide a prediction of dried food quality.

\section{ACKNOWLEDGEMENT}

The authors would like to extend their gratitude to Queensland University for providing laboratory facilities.

\section{REFERENCES}

Aguilera, J. M., \& Stanley, D. W. (1999). Microstructural principles of food processing and engineering: Maryland: Kluwer Company.

Barati, E., \& Esfahani, J. A. (2012). Mathematical simulation of convective drying: Spatially distributed temperature and moisture in carrot slab. International Journal of Thermal Sciences, 56, 86-94.

Chandra, R., Singh, S. P., \& Gupta, K. (1999). Damping studies in fiber-reinforced composites-a review. Composite structures, 46(1), 41-51.

Chou, S. K., \& Chua, K. J. (2001). New hybrid drying technologies for heat sensitive foodstuffs. Trends in Food Science \& Technology, 12(10), 359-369.

Halder, A., Dhall, A., \& Datta, A. K. (2011). Modeling transport in porous media with phase change: Applications to food processing. Journal of Heat Transfer, 133(3), 031010.

Joardder, M. U. H., Kumar, C., \& Karim, A. (2013). Effect of moisture and temperature distribution on dried food microstucture and porosity. Paper presented at the Proceedings of From Model Foods to Food Models: The DREAM Project International Conference.

Karim, M. A., \& Hawlader, M. N. A. (2005). Mathematical modelling and experimental investigation of tropical fruits drying. International Journal of Heat and Mass Transfer, 48(23), 4914-4925.

Kumar, C., Karim, A., Joardder, M. U. H., \& Miller, G. (2012). Modeling heat and mass transfer process during convection drying of fruit. Paper presented at the The 4th International Conference on Computational Methods (ICCM2012).

Maskan, A., Kaya, S., \& Maskan, M. (2002). Effect of concentration and drying processes on color change of grape juice and leather (pestil). Journal of Food Engineering, 54(1), 75-80. 
Mohammadi, A., Rafiee, S., Emam-Djomeh, Z., \& Keyhani, A. (2008). Kinetic models for colour changes in kiwifruit slices during hot air drying. World Journal of Agricultural Sciences, 4(4).

Orsat, V., Yang, W., Changrue, V., \& Raghavan, G. (2007). Microwave-assisted drying of biomaterials. Food and Bioproducts Processing, 85(3), 255-263.

Paulus, I., \& Schrevens, E. (1999). Evaluating and modelling the size classification of apples. Journal of agricultural engineering research, 74(4), 411-419.

Peng, Y., \& Lu, R. (2006). Improving apple fruit firmness predictions by effective correction of multispectral scattering images. Postharvest biology and technology, 41(3), 266-274.

Perera, C. O. (2005). Selected quality attributes of dried foods. Drying Technology, 23(4), 717-730.

Rahman, M. S. (2009). Food stability beyond water activity and glass transtion: Macromicro region concept in the state diagram. International Journal of Food Properties, 12(4), 726-740.

Rakesh, V., Seo, Y., Datta, A. K., McCarthy, K. L., \& McCarthy, M. J. (2010). Heat transfer during microwave combination heating: Computational modeling and mri experiments. AIChE journal, 56(9), 2468-2478.

Reeve, R. (1970). Relationships of histological structure to texture of fresh and processed fruits and vegetables. Journal of texture studies, 1(3), 247-284.

Romano, G., Argyropoulos, D., Nagle, M., Khan, M., \& Müller, J. (2012). Combination of digital images and laser light to predict moisture content and color of bell pepper simultaneously during drying. Journal of Food Engineering, 109(3), 438448.

Wang, W., \& Chen, G. (2003). Numerical investigation on dielectric material assisted microwave freeze-drying of aqueous mannitol solution. Drying Technology, 21(6), 995-1017.

Wilkinson, C., Dijksterhuis, G., \& Minekus, M. (2000). From food structure to texture. Trends in Food Science \& Technology, 11(12), 442-450. 